\section{An Interview} with Mark Aaron Polger, Editor of Marketing Libraries Journal

Correspondence concerning this column should be directed to Nicole Eva and Erin Shea; e-mail: nicole.eva@uleth.ca and eshea@fergusonlibrary.org.

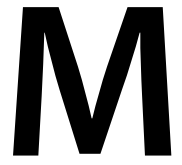

ark Aaron Polger is the First Year Outreach Librarian at the College of Staten Island, City University of New York (CUNY), where his responsibilities include promoting library services and resources as well as providing instruction to first year students. Polger is also an Information Literacy Instructor at ASA College. His research interests include library marketing, outreach, and user experience design. $\mathrm{He}$ is active in LLAMA as the chair of the PR XChange Committee as well as the co-chair of the Annual PR XChange Awards Competition. Regionally, he is an active executive board member of ACRL/NY (Association of College and Research Libraries, Greater Metropolitan New York Area), where he serves on the planning committee of the annual symposium and co-chairs the User Experience Discussion Group. Locally, he co-chairs meetings in New York City for ACRL National's Library Marketing and Outreach Interest Group. He is also a member of the planning committee of the annual Library Marketing and Communications Conference (LMCC). He is co-chair of the LACUNY (Library Association of the CUNY) Library Marketing and Outreach Roundtable Discussion Group.

Currently, Polger is the founder and editor-in-chief of the new open-access, peer-reviewed Marketing Libraries Journal, which was launched in fall 2017.

Originally from Montreal, Canada, Polger holds a BA in Sociology from Concordia University (1999), an MLIS from the University of Western Ontario (2000), an MA in Sociology from University of Waterloo (2004), and a BEd in Adult Education from Brock University (2009). He is currently a third-year PhD student in the Curriculum, Instruction, and the Science of Learning Program at SUNY University at Buffalo. He moved to New York City in 2008.

The first issue of Marketing Libraries Journal was published in fall 2017. We wanted to ask Mark about his inspiration to create this new publication.-Editors

Q: What made you want to create Marketing Libraries Journal? What type of niche do you hope it will fill?

In my years of conducting academic research on the marketing of libraries, I could not locate a specific academic journal that is solely devoted to library marketing. I thought to myself, "Hey, I could develop an open-access scholarly journal with the help of many like-minded volunteers." It took several years of thinking and planning, and then in January 2017 I launched the journal. My hope is to have a 


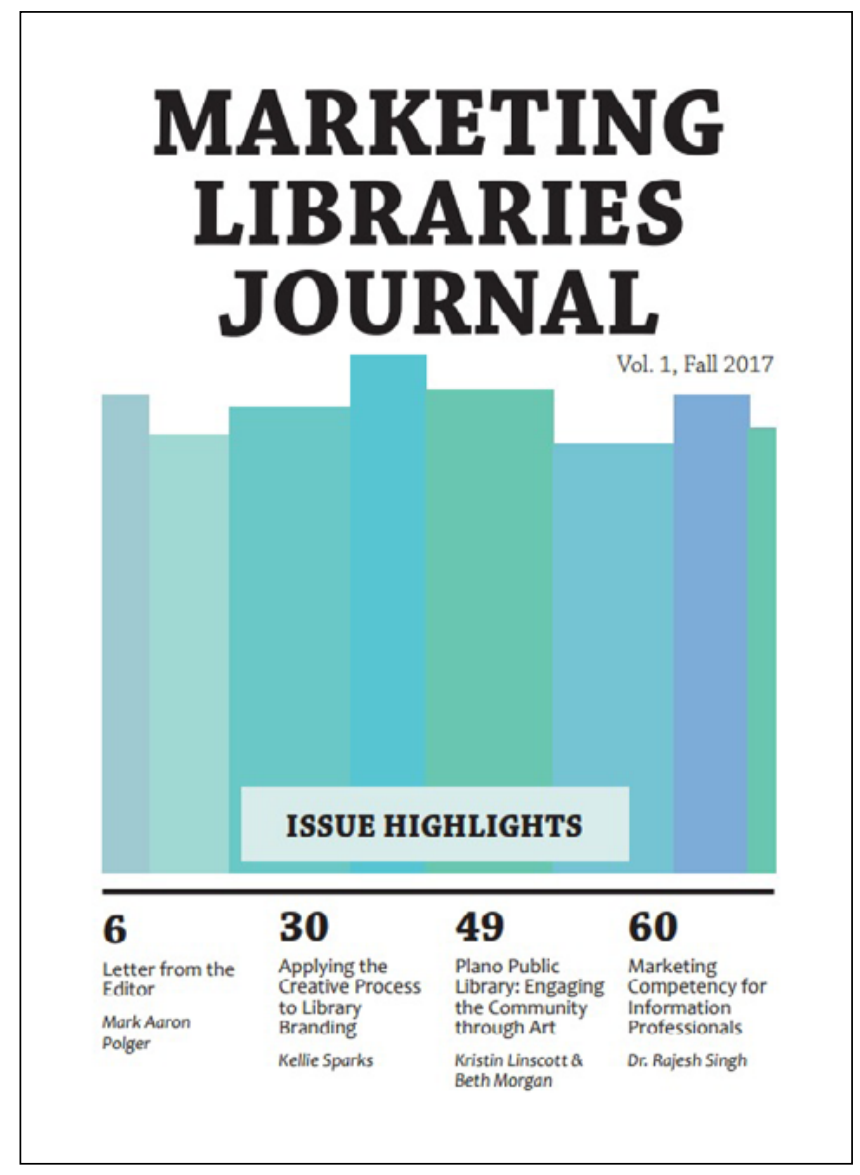

venue where authors can contribute to the scholarship of library marketing, and this journal will provide a free platform for librarians and library marketing professionals of all libraries across the United States and beyond.

Q: What got you interested in the marketing and promotional aspects of library work?

I graduated library school in the summer of 2000, and my first library job was in 2001 as a children's librarian. I was responsible for stepping outside the library to "pitch" the summer reading program in my city at the time (Toronto, Canada). I realized that visiting high schools, daycare centers, and community centers provided me with great outreach experience. I was also charged with creating promotional materials to get more children involved. Children's librarians across the entire Toronto Public Library System were charged with promoting the summer reading program, but this provided great experience for me. Later in my career, when I was a medical librarian in a hospital, I was charged with creating a mini marketing campaign where my goal was to increase the number of instructional sessions amongst physicians and clinical staff. With a laptop on a cart, a simple marketing message (Information Takeout and Delivery), and built-in assessment, our goal was to take library instruction services outside the medical library and into the clinical units. Within a year, our instruction sessions had doubled and there was increased awareness of library services and resources at my local hospital. I realized that for many public service librarians, marketing duties might be part of the job. Marketing is not a bad word, even though so many of us associate it with dishonest advertising executives or car salesmen. Marketing the library represents a very important part of raising the profile of the library facility, its services, and its resources.

\section{Q: Can you describe the process of getting a new journal} off the ground?

The first thing I did was create a mission statement that would outline the scope of the journal. I looked at other academic journals and the scope of topics published. There were some academic journals that published articles that related to the marketing of libraries, but there was no journal solely devoted to it. There was Marketing Library Services (MLS), but that was more like a trade publication rather than an academic journal. MLS is also subscription-based, and I wanted this journal to be completely free for readers and authors. I decided to register the name marketinglibraries.org and name the journal Marketing Libraries Journal (MLJ)_-simple and straightforward. I registered a temporary ISSN and I sent a call for volunteers to serve on the editorial board. I was seeking both column editors for different topic columns and a diverse collection of peer reviewers. I decided that the journal would publish both scholarly articles that would undergo a double-blind review process and other articles that would undergo a less rigorous editorial review process.

\section{Q: What kinds of difficult decisions did you have to make} in the process of creating a new journal?

I wanted the journal to be distinct and different from Marketing Library Services. I decided not to include book reviews since I wanted to focus on reviewing technology tools and websites, as opposed to reviewing books. I also wanted there to be more columns that were not peer reviewed, as it would provide the reader with more practical pieces. I also wanted the journal to be exclusively online and completely open access to both the reader and author. There are no author processing fees and the author retains copyright. They are permitted to post their completed articles on their personal websites and in academic digital repositories.

\section{Q: What lessons have you learned in that process?}

I have learned the art of patience. Author submissions take time and readership takes time. I have learned that it takes time for a journal to take off and that some authors are hesitant to submit their manuscripts to an open-access journal. I have also learned how to be a project manager to coordinate the processes with a team of more than forty people. This is a fairly new skill of mine since I have never managed people before. 
Q: Why did you decide to make it an open-access journal?

I believe that scholarship should be made available for anyone to read and share. It is so easy to set up a website, and as an author of academic articles, I want my scholarship to be available to other scholars. It bothers me when my article has been accepted for publication and I must "give up" my copyright. Very often, I do not have free access to read the very article I submitted, based on my free labor.

Q: How have you recruited editors, board members, peer reviewers, and authors?

I posted a call for volunteers on many library listservs. The library marketing community is pretty small. There are a few listservs, and one major annual conference (Library Marketing and Communications Conference); there is also a sub-group of the American Library Association called Library Leadership and Management Association (LLAMA), as well as two major library marketing award competitions. I am fortunate that I know many library marketing professionals so I had no trouble "spreading the word."

Q: What type of readership did your first issue receive?

I'm just analyzing readership right now but I think half of my readership would be from public and half from academic libraries.

Q: How many submissions did you receive for your first issue? What was your acceptance rate?

We received more than thirty submissions for our first issue. We received about five scholarly submissions, and based on our panel of peer reviewers, we accepted one "scholarly" manuscript for the first issue and six "practical" manuscripts for our columns.

\section{Q: What kind of articles were in the first issue?}

Our first issue contained a diverse collection of manuscripts. Our feature article focused on an analysis of the marketing education curriculum in LIS programs in Canada and the United States. Other articles focused on tools used for marketing (Canva), reflecting on the creative process for library branding, best practices for video marketing, internal marketing, using art in libraries to engage your audience, and awareness campaigns for library foundations.

\section{Q: What kind of articles would you like to see more of in the second issue?}

For the next issue, I would like to see more articles about marketing campaigns and best practices for libraries with low (or no) marketing budgets. I hope to see articles that discuss assessment and return on investment (ROI), as well as strength-weakness-opportunity-threat (SWOT) analyses.

\section{Q: What is your ultimate goal for this journal?}

My ultimate goal for this journal is for authors to share their "highs" and "lows" and "lessons learned." I hope that readers can be inspired to try these marketing initiatives in their own libraries. I also hope to get articles from all types of libraries from around the world.

Q: If you had to do it again, would you still want to start a new journal?

Yes, this past year has been busy but a great learning experience for me. The editorial board, reviewers, communication officers, and production team of copyeditors and layout editors have been so supportive and collegial. I have been very fortunate that I have received so much help, advice, and guidance during this past year. I hope the second issue will be as easy as the first.

Thanks Mark! If you'd like to check out Marketing Libraries Journal, either as a reader or a potential author, it can be found at http://journal.marketinglibraries.org/. 